ORIGINAL ARTICLE

\title{
Surfing, self-medicating and safety: buying non-prescription and complementary medicines via the internet
}

\author{
T L Bessell, J N Anderson, C A Silagy, L N Sansom, J E Hiller
}

Qual Saf Health Care 2003;12:88-92

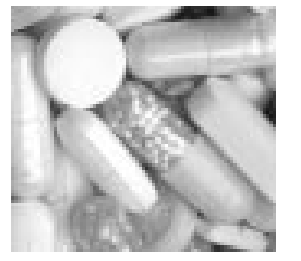

See editorial commentary, p 86

See end of article for authors' affiliations

.....................

Correspondence to: Ms T Bessell, Monash Institute of Health Services

Research, Monash University, Clayton, Victoria, Australia 3168 ; tracey.bessell@ med.monash.edu.au

Accepted for publication 1 August 2002
Objective: To examine whether the sale of medicines via the internet supports their safe and appropriate use.

Design: e-Pharmacy websites were identified using key words and a metasearch engine and the quality of information published on these websites was surveyed using the DISCERN tool. A case scenario and internet pharmacy practice standards were also used to evaluate the quality of care delivered.

Setting and participants: Between July and September 2001104 websites were surveyed and 27 sent either Sudafed (pseudoephedrine HCl), St John's wort products, or both to a residential address in Melbourne, Australia.

Main outcome measures: Quality of health information (DISCERN ratings), information exchanged between e-pharmacy staff and consumers, and product and delivery costs.

Results: Of 104 e-pharmacies from at least 13 different countries, 63 websites provided some health information but overall the quality of the information was poor. Only three website operators provided adequate advice to consumers to avoid a potential drug interaction. The costs for a daily dose of pseudoephedrine $\mathrm{HCl}(240 \mathrm{mg})$ ranged from $\mathrm{A} \$ 0.81$ to $\mathrm{A} \$ 3.04$, and delivery costs from $\mathrm{A} \$ 3.28$ to A $\$ 62.70$.

Conclusion: Consumers who self-select medicines from websites have insufficient access to information and advice at the point of ordering and on delivery to make informed decisions about their safe and appropriate use.
$\mathrm{T}$ he internet provides consumers with global access to health information, services and support. It has revolutionised the sale of medicines so that consumers can selfselect and buy medicines, often delivered across national and state boundaries, without face to face interaction with a health professional. e-Pharmacies are websites selling prescription only medicines and other products including non-prescription and complementary medicines.

To ensure the optimal use of medicines, consumers should have timely access to quality information about their benefits, risks, and appropriate usage. ${ }^{1}$ Consumers want information about medicines but have different individual needs. ${ }^{23}$ Health professionals who prescribe or dispense medicines have professional, ethical, and legal responsibilities to provide consumers with quality information and facilitate the safe and appropriate use of medicines. Whether e-pharmacies provide such information or advice is largely unknown.

Previous studies of e-pharmacies are limited to American websites or those selling lifestyle medications, including sildenafil and finasteride. ${ }^{4-10}$ Most studies regarding quality of online information focus on specific diseases or treatments, rather than the information and advice associated with the delivery of pharmaceutical services.

As controversy brews over the announcement of a German health insurance company that encourages consumers to buy medicines via the internet, ${ }^{11}$ this study aims to examine whether consumers can do so safely. It is the first study to evaluate the quality of information published on global e-pharmacy websites and to determine what happens when a consumer orders a non-prescription or complementary medi- cine from an e-pharmacy. In particular, we examined whether staff exchanged information with, and provided relevant advice to, consumers to promote the safe and appropriate use of non-prescription and complementary medicines.

\section{METHODS}

In May 2001 e-pharmacy websites were identified using Copernic (www.copernic.com), a metasearch engine that simultaneously searches 10 global commercial search engines. Search terms employed were "internet pharmacies", "internet pharmacy", "internet medicines", "online pharmacies", "online pharmacy", and "online medicines". Websites recording multiple hits were included only once in the sampling frame. Those that only offered electronic transfer of prescriptions from doctor to pharmacy or prescription refills (increasingly common in the USA), three members only sites, four sites written in languages other than English, two sites with transmission errors, and eight sites under development were excluded.

Between July and September 2001 we surveyed all websites in the sampling frame. The survey collected data in two distinct sections - the quality of health information published on e-pharmacies and a case study where medicines were purchased via the internet.

The quality of health information was evaluated using the DISCERN rating instrument which was specifically developed and validated to assess a broad range of online and written 
Box 1: Case scenario (35 year old Australian woman)

Place an order for Sudafed (preferred brand) or pseudoephedrine $\mathrm{HCl}(30-120 \mathrm{mg})$ (single therapeutic ingredient), quantity 10-60 capsules/tablets and St John's wort $100 \mathrm{mg}+$, quantity 10-60 (no preferred brand) from an online supplier of scheduled medicines. Choose the cheapest Sudafed or St John's wort product if multiple options are available.

The Sudafed or pseudoephedrine $\mathrm{HCl}$ product is for your own use. You have had a runny nose for a couple of days and a friend suggested you try it; you have not used this product before or tried anything else to treat the problem. The St John's wort is also for your own use. You have been feeling really flat and low and you read about St John's wort in a magazine; you have not used this product before. You have taken Prozac (fluoxetine) for depression for the past 3 months after being in a car accident. You are not taking any other medications and have no other illnesses.

consumer health information. ${ }^{12}$ DISCERN consists of 15 questions, each representing a unique quality criterion, plus an overall quality rating.

The case study was undertaken by one of us (TB) acting as a consumer who attempted to purchase one non-prescription and one complementary medicine using a set case scenario (box 1). Standardised patients are a useful method to assess the quality of primary health care including pharmacy practice. ${ }^{13-17}$ All products were to be delivered to a residential address (not a post office box) in Melbourne, Australia.

We chose Sudafed (pseudoephedrine hydrochloride) and St John's wort (Hypericum perforatum) tablets for the case scenario because they are both commonly used and widely available. Pseudoephedrine $\mathrm{HCl}$ is often illegally misused to manufacture amphetamines ${ }^{18-20}$ and in Australia its importation requires a licence from the Therapeutic Goods Administration. ${ }^{21}$ St John's wort products interact with many medicines by altering drug metabolism or increasing central nervous system serotonin levels. ${ }^{22}$ It can interact with medicines including cyclosporin, digoxin, oral contraceptives, theophylline, wafarin, anticonvulsants (carbamazepine, phenobarbitone and phenytoin), selective serotonin reuptake inhibitors (SSRIs) and related drugs (citalopram, fluoxetine, paroxetine, sertraline, nefazodone), triptans (sumatriptan, naratriptan, rizatriptan and zolmitriptan), human immunodeficiency virus (HIV) protease inhibitors, and HIV nonnucleoside reverse transcriptase inhibitors. ${ }^{22}$ Serotonergic syndrome is characterised by changes in mental status and motor and autonomic function and is a potentially serious adverse drug event that may occur when St John's wort and fluoxetine are taken concurrently.

Data on the nature of patient information collected by pharmacy staff; the provision of written information and advice by pharmacy staff; product recommendations; referrals; payment security; delivery costs, times and methods; customs inspections; and the condition of the product received were collected. The information exchanged with and advice provided to consumers by e-pharmacy staff was assessed using pharmacy practice standards and current guidelines. ${ }^{23}$ We also assessed whether e-pharmacies had processes in place to detect the potential drug interaction between St John's wort and fluoxetine. (A copy of the survey tool is available upon request from the first author.)

The Monash University Standing Committee on Ethics in Research Involving Humans gave ethics approval for this study. Informed consent was not sought from e-pharmacy operators before buying these medicines because of the simulated nature of the project. However, in accordance with the recommendations of the ethics committee, we sent e-pharmacies that delivered medicines a hard copy of the data collected from their individual website 1 month after delivery and each had the opportunity to withdraw their results from the study.

The data were summarised using descriptive statistics.

\section{RESULTS}

\section{Quality of information}

We identified and surveyed 104 unique e-pharmacy websites from at least 13 different countries; 63 (61\%) provided some health information, 51 (49\%) provided some information about medicines, 31 (30\%) published information on disease states, 17 (16\%) provided lifestyle information, 41 (40\%) provided no information, and $53(51 \%)$ published poor quality information of limited or no benefit (table 1).

Of the 104 e-pharmacies, $52(50 \%)$ allowed consumers to search by trade name, 55 (53\%) by therapeutic class, and 22 $(21 \%)$ by therapeutic substance, while 35 (34\%) offered no search function at all. Thirty (29\%) websites displayed external links, most commonly to consumer health support groups and online medical libraries, but others included one online gambling site and two news websites.

Twenty five websites published information about pseudoephedrine $\mathrm{HCl}$. Of these, 21 (84\%) published useful information (DISCERN rating 4 or 5 ) about the benefits associated with taking pseudoephedrine $\mathrm{HCl}$ but only 13 (52\%) published such information about risks. Nineteen websites published information about St John's wort products and overall the information about the benefits and risks of these products was more balanced (17 and 18 websites, respectively). However, the information was often of a general nature and less useful. For example, "this medication may interact with other medicines" rather than "this medicine interacts with a list of specific therapeutic substances".

\section{Case study}

Of the 104 e-pharmacies, 31 (30\%) and 41 (40\%) websites sold pseudoephedrine $\mathrm{HCl}$ and St John's wort, respectively. Fifteen of the $31(48 \%)$ delivered pseudoephedrine HCl (14 Sudafed and one local generic product) while 26 of the 41 (63\%) delivered various St John's wort products to Australia. Fourteen e-pharmacies delivered both products and a total of 27 packages were received from Australia, Canada, New Zealand, UK, and the USA. Sixteen (52\%) and $15(37 \%)$ of the e-pharmacies selling pseudoephedrine $\mathrm{HCl}$ and St John's wort, respectively, did not deliver these medicines to Australia, largely because 31 $(30 \%)$ of the 104 e-pharmacies only deliver such medicines within their national borders. No e-pharmacies withdrew their results.

Of the 27 e-pharmacies that supplied medicines, 13 (48\%) required consumers to register a user name and password. Twenty five websites (93\%) confirmed the order and delivery details of products via email. All sites used secure socket layer (SSL) technology for payment transactions. The operation of these e-pharmacies appeared to involve registered pharmacists and no websites sold prescription only medicines without a prescription written by a doctor.

Of the 27 e-pharmacies that supplied medicines, 15 (56\%) provided information about directions for use, eight (30\%) about treatment length, $14(52 \%)$ about potential adverse events, $11(41 \%)$ about interactions, and four (15\%) offered what to do if ther condition did not improve. No sites suggested associated ancillary lifestyle changes, and no e-pharmacy staff recommended alternative or additional products. Upon delivery the only written information about the medicines received was one manufacturer's information sheet regarding the use of pseudoephedrine $\mathrm{HCl}$ and one information sheet regarding St John's wort and potential drug interactions. 
Table 1 Frequency of DISCERN ratings of health information given by e-pharmacies by geographical location

\begin{tabular}{|c|c|c|c|c|c|c|c|}
\hline \multirow[b]{2}{*}{ Location } & \multirow[b]{2}{*}{ Total no } & \multirow[b]{2}{*}{ No } & \multicolumn{5}{|c|}{ DISCERN rating* } \\
\hline & & & 1 & 2 & 3 & 4 & 5 \\
\hline \multicolumn{8}{|l|}{ Australasia } \\
\hline Australia & 12 & 2 & & 4 & 6 & & \\
\hline New Zealand & 13 & 3 & 1 & 4 & 5 & & \\
\hline \multicolumn{8}{|l|}{ North America } \\
\hline Bermuda & 1 & & & 1 & & & \\
\hline Canada & 4 & 2 & 1 & 1 & & & \\
\hline Mexico & 1 & 1 & & & & & \\
\hline USA & 40 & 14 & 1 & 9 & 7 & 4 & 5 \\
\hline \multicolumn{8}{|l|}{ Asia } \\
\hline India & 2 & 1 & 1 & & & & \\
\hline China & 1 & 1 & & & & & \\
\hline Philippines & 1 & & 1 & & & & \\
\hline \multicolumn{8}{|l|}{ Europe } \\
\hline Italy & 1 & 1 & & & & & \\
\hline Spain & 1 & & & 1 & & & \\
\hline Switzerland & 1 & 1 & & & & & \\
\hline UK & 4 & 1 & 2 & & & 1 & \\
\hline Unknown & 22 & 14 & 1 & 6 & 1 & & \\
\hline Total & 104 & 41 & 7 & 26 & 20 & 5 & 5 \\
\hline \multicolumn{8}{|c|}{$\begin{array}{l}\text { *DISCERN ratings: } 5=\text { high, indicates that the publication is of "good" quality (a useful and appropriate } \\
\text { source of information about treatment choices); } 3 \text { =moderate, indicates that the publication is of "fair" quality } \\
\text { (a useful source of information about treatment choices but has some limitations; additional information or } \\
\text { support would definitely be needed); } 1=\text { low, indicates that the publication is of "poor" quality (has serious } \\
\text { shortcomings and is not a useful or appropriate source of information about treatment choices; it is unlikely to } \\
\text { be of any benefit and should not be used). }\end{array}$} \\
\hline
\end{tabular}

Of the 26 e-pharmacies that supplied St John's wort products, five (19\%) websites asked for consumer information that could have enabled staff to detect the potential drug interaction involving fluoxetine and St John's wort, but only three $(12 \%)$ contacted the consumer about this concern. The three e-pharmacies initially communicated via email asking for additional contact. Three e-pharmacists subsequently counselled the consumer by telephone and correctly referred the consumer to see her doctor before commencing selfmedication with St John's wort. The staff of the remaining 21 $(81 \%)$ e-pharmacies could not detect this potential drug interaction because they failed to exchange relevant information with consumers.

Products were received by post $(12,44 \%)$, registered post $(11,41 \%)$, and courier $(4,15 \%)$ and signatures were required on $15(56 \%)$ occasions. Eight of $16(50 \%)$ international deliveries were opened, inspected, and resealed by Australian customs officers. Two packages (13\%) containing pseudoephedrine $\mathrm{HCl}$ products had no tangible evidence of customs inspection. Upon delivery, we identified the sender of 16 (60\%) packages by information visible on the exterior of the package, $19(70 \%)$ by descriptions of package contents, and three ( $11 \%)$ packages by deduction using postmarks and dates. Sixteen $(60 \%)$ were packed in boxes and $11(40 \%)$ in envelopes. Twenty two $(81 \%)$ packages contained bubble wrap or similar materials. Despite these packaging precautions, two (7\%) products were damaged at the time of delivery.

Specific errors included one delivery of an out of date St John's wort product (expired August 2001, delivered September 2001) and one package was sent to the billing address instead of the residential address. The e-pharmacy that supplied the out of date product was contacted by email and a refund was offered. One pharmacy also substituted a different brand of St John's wort from that originally ordered with no notification or explanation about the change.

The product costs, postage and handling charges, and delivery times were highly variable. For example, the product costs of a total daily dose of pseudoephedrine $\mathrm{HCl} 240 \mathrm{mg}$ ranged from $\mathrm{A} \$ 0.82$ to $\mathrm{A} \$ 3.04$ (mean $\mathrm{A} \$ 1.50,95 \%$ CI 1.13 to 1.87 ). Costs of St John's wort products also varied but are not comparable because of inconsistent recommended daily dosages and the non-standardised nature of some complementary medicine products. Postage and handling charges ranged from $\mathrm{A} \$ 3.28$ to A $\$ 62.70$ (median A \$7.54). The product, postage and handling costs were most expensive for deliveries from the USA. All costs are given in Australian dollars (A\$) where $\mathrm{A} \$ 1=£ 0.37$ and US\$0.52. Delivery times ranged from 2 to 18 days (mean 6 (95\% CI 4.5 to 7.5 )).

\section{DISCUSSION}

Australian internet pharmacy practice standards state that "the pharmacist provides medicines and devices through the internet in a manner which safeguards the privacy and confidentiality of the patient, delivers the correct product with appropriate information to the patient, and promotes safe, correct and appropriate use of medicines." ${ }^{24}$ Despite the introduction of similar standards and guidelines in Canada, New Zealand, the UK and the USA, ${ }^{25-28}$ we found that most e-pharmacies (including those operating in these countries) selling non-prescription and complementary medicines failed to uphold the intent of these standards. This study shows that consumers who self-select non-prescription medicines from e-pharmacies are at risk of medication misadventures.

Consumers cannot make an informed decision about purchasing a medicine using information provided by e-pharmacies because balanced information about the benefits and risks of taking medicines was largely not available or of poor quality. Furthermore, written information was rarely provided upon delivery. Although the packaging contains some information, it alone does not adequately protect consumers from harm. ${ }^{29}$ Pharmacists have a duty of care to ensure that consumers are provided with sufficient information to assist the safe and effective use of medicines to 
optimise health outcomes. ${ }^{30}$ e-Pharmacy operators must be encouraged to provide consumers with quality balanced pharmaceutical information at the right place and time: information linked to individual products at the point of ordering and upon delivery.

Medical and consumer literature identifies the importance of an exchange and sharing of information between consumers and health professionals to achieve positive health outcomes. $^{31}$ In traditional "bricks and mortar" practices consumers can be provided with, or ask for, advice about medicines, and such advice is generally valued. ${ }^{32}$ Pharmacists also refer consumers to their doctor when necessary. UK research has shown that, in about a quarter of pharmacistconsumer consultations, no sale is made and pharmacists often recommend customers to see their doctor. ${ }^{33}$ In an online environment the exchange of information between pharmacists and patients requires easy to use and secure electronic communication processes. It is therefore disturbing that the majority of e-pharmacy staff were unable to detect a potentially serious drug interaction because processes were not in place to obtain relevant information about consumers, including their current medications.

One of the potential strengths of the internet is to provide consumers with informed choices. Medicines have many different trade names, and the same therapeutic substances have different approved names in different countries-for example, paracetamol (UK) and acetaminophen (USA). Consumers wishing to compare brands, formulations, and prices of similar products should be able to search by therapeutic substance or class, but less than half the e-pharmacies provided such a capability. e-Pharmacies could incorporate these and other consumer friendly online features including drug-drug and drug-disease interaction checks, selfmonitoring tools, and medication charts and diaries.

Despite cost being a major driver of online consumerism and the relatively free trade of non-prescription medicines, we observed large price disparities between medicines sold by e-pharmacies operating in different countries. Consumers are more likely to realise cost savings from e-pharmacies when purchasing multiple items, and whether they consequently buy more products than those immediately required is unknown.

Ultimately, consumers will decide whether or not to purchase medicines from e-pharmacies, as safeguarding the privacy and confidentiality of the consumers is paramount to its sustainability as a commercial resource. Although discrete packaging protects consumers from potential embarrassment, the origin of medicines sent via the postal system should be identifiable by customs officers and consumers. All packages should include contact details of the sender. Furthermore, errors and the damaged condition of some products upon delivery may deter consumers from repeated use of e-pharmacies.

The results of this study are tempered by some methodological limitations. Although we searched broadly using a rigorous identification strategy, it is difficult to determine whether this sample of 104 websites was entirely representative because the total current number of e-pharmacies operating at any one time is unknown. Due to the nature of the internet, it is difficult to evaluate whether an e-pharmacy is bona fide unless the site displays a seal that can be electronically verified by an independent pharmacy statutory body. ${ }^{27}$ Furthermore, it is almost impossible to know with whom you are dealing or the location or ownership of e-pharmacies. Of the 27 that supplied medicines to us, all appeared to involve a qualified pharmacist, but whether qualified or unqualified staff supervised our medication order was unknown. Most countries legally permit the export and import of nonprescription medicines for personal use, but only approximately half of the e-pharmacies selling pseudoephedrine $\mathrm{HCl}$ and St John's wort products delivered such medicines to Aus-

\section{Key messages}

- Health information published on many e-pharmacy websites is absent or of poor quality.

- Despite the introduction of e-pharmacy practice standards, consumers may not be safeguarded from inadvertent medication misadventures.

- Consumers should be provided with balanced information about the benefits and risks of medicines at the point of ordering and upon delivery.

- Consumer education about the benefits and risks of buying medicines online is needed.

tralia. The reasons for this are unknown, but limited the sample size of the case study. Despite these limitations, this study provides a unique insight into e-pharmacy practice in 2001.

We conclude that internet technologies should be used to develop ethical and innovative practice models that make the management of medications for consumers easier, simpler, and safer to achieve positive health outcomes, but surfing and self-medicating is currently not safe. Consumer education about the benefits and risks of buying medicines via the internet is needed because national e-pharmacy standards alone do not adequately address the overall lack of information and advice provided. It is vital that such standards address the needs for pharmacists and consumers to exchange information and prevent self-medication misadventures. To support the safe and appropriate use of non-prescription and complementary medicines, e-pharmacies must go beyond satisfying minimum practice standards and deliver consumer focused services including the provision of quality medicines information linked to the product at the time of ordering, and written information on the delivery of medicines.

\section{Authors' affiliations}

T L Bessell, J N Anderson, C A Silagy, Monash Institute of Health Services Research, Monash University, Victoria, Australia

L N Sansom, School of Pharmaceutical, Molecular and Biomedical Sciences, University of South Australia, SA, Australia

J E Hiller, Department of Public Health, University of Adelaide, SA, Australia

\section{REFERENCES}

1 Australian Commonwealth Department of Health and Aged Care. National medicines policy 2000. Canberra: Publications Production Unit, Commonwealth Department of Health and Aged Care, 1999

2 Barber N. Ensuring patients' satisfaction with information about their medicines. Qual Health Care 2001;10:130-1.

3 Consumers' Health Forum of Australia. Pharmaceuticals project final report. Canberra: Consumers' Health Forum of Australia, 1995.

4 Peterson A. A Survey of selected internet pharmacies in the United States. J Am Pharm Assoc 2001;41:205-12.

5 Bloom BS, lannacone RC. Internet use for prescription pharmaceuticals. Ann Intern Med 1999;131:830-3.

6 Virginia Board of Medicine, Department of Health Professions. Study of the sale of prescription drugs via the internet pursuant to HJR 759. 1999. Formerly available at www.dhp.state.va.us/BHP/ internet_prescribing_study_report.htm (accessed 16 October 2000).

7 Yang Z, Peterson RT, Huang L. Taking the pulse of internet pharmacies. Marketing Health Serv 2001;21:4-10.

8 Armstrong K, Schwartz JS, Asch DA. Direct sale of sildenafil (Viagra) to consumers over the internet. N Engl J Med 1999;341:1389-92.

9 Eysenbach G. Online prescribing of sildenafil (Viagra) on the world wide web. J Med Internet Res 1999;1:e10.

10 Anon. Net benefit? Health? Which 2000;16-19.

11 Tuffs A. Internet sales threaten drug companies' supremacy. BM 2002;324:998

12 Charnock D. The DISCERN handbook: Quality criteria for consumer health information on treatment choices. Oxford: Radcliffe Medical Press, 1998.

13 Glassman PA, Luck J, O'Gara EM, et al. Using standardised patients to measure quality: evidence from the literature and a prospective study. It Comm J Qual Improv 2000;26:644-53.

14 Anderson C, Alexander A. Response to dysmenorrhoea: an assessment of pharmacist's knowledge and its application in practice Int J Pharm Pract 1993;2:180-3. 
15 Anderson C. A controlled study of the effect a health promotion training scheme on pharmacists' advice about smoking cessation. Soc Admin Pharm 1995; 12:115-23.

16 Krska J, Kennedy EJ. Audit of responding to symptoms in community pharmacy. Int J Pharm Pract 1996;4:129-35.

17 De Almeida Neto AC, Kelly F, Benrimoj SI. Shaping practice behaviour: novel training methodology. Int J Pharm Pract 2001;9:203-10

18 Editorial. Pharmacy boards step up efforts on pseudoephedrine. Aust J Pharm 2000;81:102

19 Logan T. Sudafed shoppers. Available at http:// www.pharmacyweb.com.au/auspharmlist/2000/1 12000/082.html (accessed 24 October 2001).

20 Lees N. Large quantity of tablets found in van. Courier Mail available at http://ballarat.yourguide.com.au/ detail.asp?class=News\&story_id=68014 (accessed 24 October 2001).

21 Therapeutic Goods Administration. Substances controlled under the customs export/import legislation. Available at http:// www.tga.health.gov.au/docs/html/bringmed/customs.htm\#single (accessed 25 October 2001).

22 Therapeutic Goods Administration. Information sheet for health care professionals: interactions of St John's wort (Hypericum perforatum) preparations. Available at http://www.health.gov.au:80/tga/docs/ html/info.htm (accessed 13 March 2002).

23 Pharmaceutical Society of Australia. Professional practice standards. Canberra: Pharmaceutical Society of Australia, 2001.

24 Pharmaceutical Society of Australia. Standard internet pharmacy March 2001. Canberra: Pharmaceutical Society of Australia, 2001
25 Canadian Pharmacists Association. Statement on internet pharmacy in Canada. Available http://www.cdnpharm.ca/cphanew/nv/ internetpharmstatementenglish.pdf (accessed 18 October 2001).

26 Royal Pharmaceutical Society of Great Britain. Professional Standards Directorate fact sheet 8: Pharmacy and the internet August 2001. Available at www.rpsgb.org.uk (accessed 18 October 2001).

27 Pharmaceutical Society of New Zealand. Internet pharmacy accreditation programme. Available at http://www.psnz.org.nz/ (accessed 20 October 2001).

28 National Association of Boards of Pharmacy. Verified internet pharmacy practice sites. Available from http://vipps.nabp.net/ (accessed 18 October 2001).

29 Herxheimer A. Many NSAID users who bleed don't know when to stop. BM 1998:316:492.

30 World Health Organisation. The role of the pharmacist in self-care and self-medication. Available at http://www.who.int/medicines/library/ dap/who-dap-98-13/who-dap-98-13.doc laccessed 25 October 2001)

31 Hopkins H, Wade T, Weir D. 'Take as directed', whatever that means. Australian Prescriber 2000;23:103-4. Available at http:// www.australianprescriber.com/magazines/vol23no5/ take_as_directed.htm (accessed 13 March 2002).

32 Taylor J. OTC counselling: review of pharmacists' performance. Medscape Pharmacists August 2001. Available at http:// www.medscape.com/Medscape/pharmacists/journal/2001/v02.n04/ mph7708.tayl/mph77 08.tayl-01.html (accessed 20 August 2001).

33 Smith FJ. Referral of clients by community pharmacists in primary care consultations. Int J Pharm Pract 1993;2:86-9. 